\title{
The Effect and Countermeasure of Magnetic Control Reactor Field Winding Induction High Pressure on the Excitation System ${ }^{1, a}$ Wang Hai, ${ }^{2, b}$ Li Chun-dong, ${ }^{2, c}$ Ma Tao, ${ }^{1, d}$ Guan Shi-shen, ${ }^{2,}$ Yang Ping \\ ${ }^{1}$ State Grid Shenyang Electric Power supply Company, Shenyang 100300,Liaoning Province China \\ ${ }^{2}$ Liaoning Electric Power Development Stock Co.,LTD,Shenyang 110179, Liaoning Province China Inmt0408@163.com
}

Keywords:Magnetically controlled reactor; exciting winding; induction high tension; thyristor; neutralizing transformer

\begin{abstract}
The AC voltage at the both ends of the excitation winding of the magnetic control reactor should be zero volts, but because of the reason of magnetic control reactor structure design and the influence of such factors as the symmetrical deviation of manufacturing process, exciting winding ends there is a higher high AC voltage, even be a hidden danger of excitation faults and ontology faults. Based on the analysis of the root causes of exciting winding induction high-pressure,this paper analyses the detriments of Induction high tension, and proposes the measures to diminish the influence of Induction high tension.
\end{abstract}

\section{Introduction}

Magnetically controlled reactor plays a positive role on reactive compensation, because it has the characteristic of stepless and reactive regulation. However, operation practice shows that malfunction of magnetically controlled reactor happens occasionally [11-15]. The accident of breaking down the reactor is not rare. According to collected malfunction information, the malfunction of excitation system occupies a major proportion in the malfunction of magnetically controlled reactor. From the superficial phenomenon, malfunction of excitation system should belong to the internal reason of excitation system. Therefore, after-sale servicemen of some manufacturers once maintained the excitation system of the same magnetically controlled reactor repeatedly. However, excitation system also appeared the same malfunction after repaired for a short time. Originally, magnetically controlled reactor is the equipment with higher reliability. Why does it behave so vulnerable? According to the testing on the exciting winding of multiple magnetically controlled reactors, both ends of the magnetically controlled reactor's exciting winding have AC voltage for hundreds of volts or even thousands of volts. The existence of this induced voltage becomes the hidden danger of causing the malfunction of magnetically controlled reactor.

\section{Induced Voltage of Magnetically Controlled Reactor}

Excitation system is a control device that provides excitation current for magnetically controlled reactor and adjusts reactor impedance by changing the magnitude of excitation current. Generally speaking, excitation system can be realized through controlled rectifying circuit. Exciting winding of reactor is the loading of controlled rectifier circuit.

Strictly speaking, no matter it is internal exciting mode or external exciting mode, AC voltage at the both ends of exciting winding should be zero volt. However, because manufacturing technique of magnetically controlled reactor has the symmetrical difference, it is inevitable to have AC voltage at the both ends of exciting winding. Moreover, because technological symmetry of magnetically controlled reactor is pretty bad and mainly reflects in higher induced voltage at the both ends of exciting winding. When working current of magnetically controlled reactor happens large jumping, both ends of exciting winding will induce very high alternating voltage. By testing 
magnetically controlled reactor of $380 \mathrm{~V}$ external excitation, when excitation current steps to 50A from $0 \mathrm{~A}$, induced voltage at the both ends of exciting winding is $210 \mathrm{~V}$, which is 5 times of direct voltage, as shown in Figure 2; When excitation current steps to 0A from 50A, induced voltage at the both ends of exciting winding is $250 \mathrm{~V}$, which is over 6 times of direct voltage, as shown in Figure 3. Figure 1 is the excitation voltage waveform of magnetically controlled reactor for stable running. There is $60 \mathrm{~V}$ peak voltage.

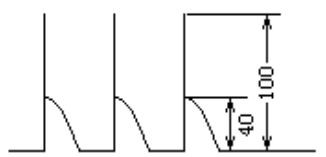

Fig.1 THE excitation voltage waveform of Excitation current for 50A stable running

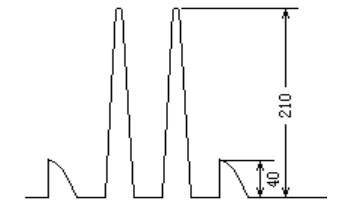

Fig.2 The excitation voltage waveform of excitation current transition from $0 \mathrm{~A}$ to $50 \mathrm{~A}$

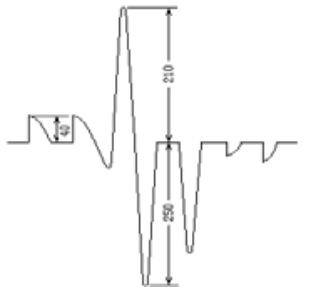

Fig.3 The excitation voltage waveform of excitation current transition from 50A to 0A

\section{The Impact on Exciting Winding Induced Voltage Rectifier Circuit}

As shown in Figure, induced voltage at the both ends of exciting winding is in parallel with the output end of controlled rectifier circuit. It seems that the output end of rectifier circuit is in parallel with the alternating voltage. When the induced voltage of exciting winding is far higher than the input voltage $\mathrm{U} 1$ of the rectifier circuit, the rectifier cell that should be conductive will be cut-off because of reverse bias. Connecting the rectifier cell that should be cut-off compulsorily not only damages the sequential relationship of rectifier circuit, but also is likely to endanger the safety of rectifier cell.

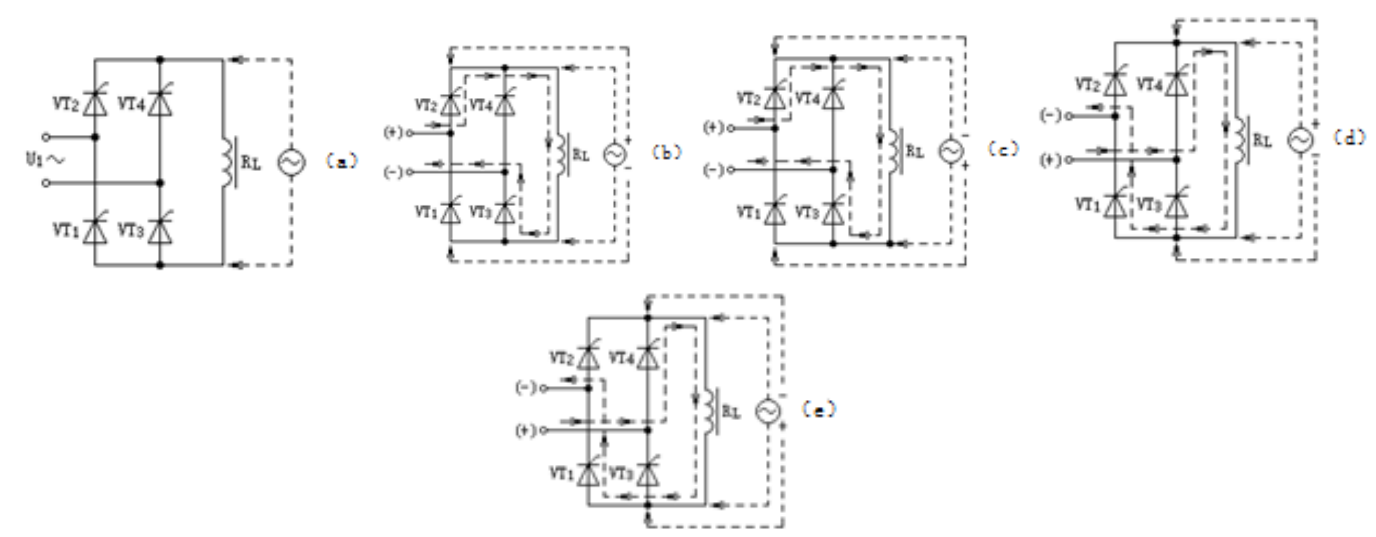

Fig.4 The impact on the exciting winding induced voltage rectifier circuit

Figure 4(a) is single phase fully controlled bridge rectifier circuit. It is the frequently-used rectifier system of external excitation of magnetically controlled reactor. RL in the figure is the exciting winding of magnetically controlled reactor. The imaginary line refers to alternating voltage, namely AC voltage of exciting winding.

When upper polarity of rectifier circuit AC input is positive, while the bottom polarity is negative, meanwhile upper polarity of induced voltage is also positive, and the bottom polarity is 
negative, thyristors VT2 and VT3 are triggered. VT1 and VT4 are cut-off. Current path of rectifier circuit is shown in Figure 4(b). In this case, if induced voltage (UG) is high enough, thyristor VT2 that should be conductive will be cut-off, because of reverse bias, resulting in no rectified current output in rectifier circuit. On the other hand, thyristor VT1 is equivalent to improve its cathode voltage because anode voltage imposes very high negative voltage. When cathode voltage is higher than reverse blocking voltage of thyristor, VT1 will be reverse breakdown and give rise to damage.

When upper polarity of rectifier circuit AC input is positive and the bottom polarity is negative, while upper polarity of induced is negative, and the bottom polarity is positive, thyristors VT2 and VT3 are triggered. VT1 and VT4 are cut-off. Current path of rectifier circuit is shown in Figure 4(c). In this case, if induced voltage (UG) is high enough, thyristor VT2 is equivalent to improve its anode voltage, resulting in booming output current. VT2 may be damaged because of overcurrent. For thyristor VT1, it may be conductive compulsorily due to higher anode voltage. VT1 may be damaged because of compulsory breakover.

When upper polarity of rectifier circuit AC input is negative and the bottom polarity is positive, while upper polarity of induced voltage is positive and the bottom polarity is negative, thyristors VT1 and VT4 are triggered. VT2 and VT3 are cut-off. Current path of rectifier circuit is shown in Figure 4(d). In this case, if induced voltage (UG) is high enough, thyristor VT4 that should be conductive will be cut-off, because of reverse bias, resulting in no rectified current output in rectifier circuit. On the other hand, thyristor VT3 is equivalent to improve its cathode voltage because anode voltage imposes very high negative voltage. When cathode voltage is higher than reverse blocking voltage of thyristor, VT3 will be reverse breakdown and give rise to damage.

When upper polarity of rectifier circuit AC input is negative and the bottom polarity is positive, while upper polarity of induced voltage is negative and the bottom polarity is positive, thyristors VT1 and VT4 are triggered. VT2 and VT3 are cut-off. Current path of rectifier circuit is shown in Figure 4(e). In this case, if induced voltage (UG) is high enough, thyristor VT4 is equivalent to improve its anode voltage, resulting in booming output current. VT4 may be damaged because of overcurrent. For thyristor VT3, it may be conductive compulsorily due to higher anode voltage. VT3 may be damaged because of compulsory breakover.

Tab.1 The impact on the field winding induced voltage controlled rectifier circuit

\begin{tabular}{|c|c|c|c|}
\hline $\begin{array}{ll}\text { Input } & \text { Voltage } \\
\text { Polarity } & \\
\end{array}$ & $\begin{array}{l}\text { Induced Voltage } \\
\text { Polarity }\end{array}$ & $\begin{array}{l}\text { Normal Working } \\
\text { Condition of Thyristor }\end{array}$ & $\begin{array}{l}\text { Possible Stage of Thyristor } \\
\text { Impacted by Induced Voltage }\end{array}$ \\
\hline Po & $\mathrm{P}$ & $\begin{array}{l}\text { VT2、VT3 breakover, } \\
\text { VT1、VT4cut-off }\end{array}$ & $\begin{array}{ll}\text { VT2cut-off , } \\
\text { breakdown }\end{array}$ \\
\hline Posi & Neg & $\begin{array}{l}\text { VT2、VT: } \\
\text { VT1、VT4 }\end{array}$ & $\begin{array}{l}\text { jercurrent } \\
\text { mpulsory break }\end{array}$ \\
\hline Neg & $\mathrm{P}$ & $\begin{array}{l}\text { VT1、VT4breakover, } \\
\text { VT2、VT3cut-off }\end{array}$ & $\begin{array}{l}\text { t-off , VT3reverse } \\
\text { own }\end{array}$ \\
\hline Negat & Nega & $\begin{array}{l}\text { VT1、VT4breakover, } \\
\text { VT2、VT3cut-off }\end{array}$ & $\begin{array}{l}\text { VT4overcurrent } \\
\text { VT3compulsory breakover }\end{array}$ \\
\hline
\end{tabular}

Because the breakdown of field may cause the damage of exciting transformer, as well as the damage of magnetically controlled reactor's exciting winding, so as to cause the damage of magnetically controlled reactor. Therefore, induced voltage at the both ends of exciting winding is the important hidden danger of causing the malfunction of magnetically controlled reactor.

The above-mentioned analysis is drawn in the premise of high enough induced voltage. It doesn't mean that there is induced voltage, controlled rectifier circuit will certainly be affected and damaged. However, higher induced voltage at the both ends of exciting winding is almost the common characteristic of all magnetically controlled reactors. Therefore, undoubtedly, it is the important hidden danger of causing malfunction of field circuit.

\section{Elimination of Exciting Winding Induced Voltage}

In two exciting modes, as shown in Figure 4, no matter it is the exciting mode in Figure 5(a) or in Figure 5(b), AC induced voltages between input ends of exciting current, D1 and D2 are zero. 
However, internal structure parameter of reactor can't be strictly consistent, resulting in ubiquity of UD1D2 $>0$. AC induced voltages between D1 and D2 for some reactors even reach several hundred voltages or higher. This lays a foundation on generating higher induced voltage, when working current of reactor steps. The most fundamental method of eliminating induced voltage at the both ends of exciting wind is to control processing technique, improve consistency of reactor's structure parameter, make reactor's UD1D2=0 for stable running, or reduce UD1D2 until it won't impact voltage level when exciter circuit works stably, ensure that induced voltage still can control impact of exciter circuit within the minimum limitation when $r$ reactor's working current steps, avoid from damaging exciter circuit caused by induced voltage, and avoid from chain reaction caused by damaged exciter circuit.

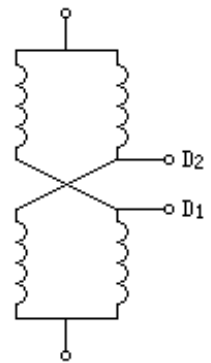

(a)

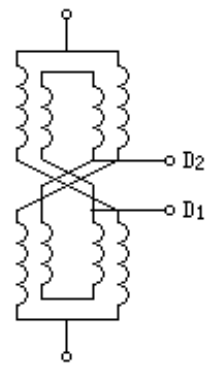

(b)

Fig.5 magnetically controlled reactor two outer excitation mode

Narrow pulse that exists in exciting voltage, as shown in Figure, can adopt RC absorption to absorb voltage spike, as shown in RC branch of Figure 6.

For the induction high pressure in Figure 2 and 3, its period can reach 10-20ms. The method of using RC absorption can't eliminate it. At this moment, it can add offset transformer(also called as longitudinal choking coil) between output end of exciter circuit and input end of magnetically controlled reactor's exciting current, namely between D1 and D2. Transformer B, as shown in Figure 6, makes the current direction of transformer winding become opposite direction and flux offset, so as to offset higher induced voltage at the both ends of exciting winding. RL in the figure is magnetically controlled reactor's exciting winding.

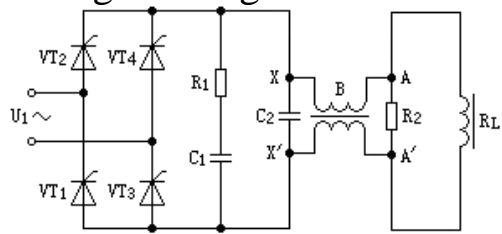

Fig.6 The measure of eliminated field winding Induced voltage

Tab.2 Circuit test data after adding offset transformer

\begin{tabular}{|c|c|c|c|c|c|c|}
\hline \multirow{2}{*}{$\begin{array}{l}\text { Input } \\
\text { Voltage } \\
\text { U1 (V) }\end{array}$} & \multirow{2}{*}{$\begin{array}{l}\text { Reactor } \\
\text { Current (A) }\end{array}$} & $\begin{array}{l}\text { Excitation } \\
\text { Parameter } \\
\text { (DC) }\end{array}$ & $\begin{array}{l}\text { Offset } \\
\text { (AC) }\end{array}$ & \multicolumn{2}{|c|}{ Transformer } & Voltage \\
\hline & & Current（A） & UAA/ & UXX/ & UAX & $\mathrm{UA} / \mathrm{X} /$ \\
\hline 230 & 40 & 20 & 106 & 3 & 52 & 52 \\
\hline
\end{tabular}

It can be observed from Table 2 that in the situation of $106 \mathrm{~V} \mathrm{AC}$ induced voltage, because of offset transformer, only $3 \mathrm{~V}$ induced voltages are reflected in the both ends of XX. It indicates that bucking effect of offset transformer is obvious on exciting winding induced voltage.

After adding offset transformer in excitation circuit, current that flows through mainly is direct current, which almost has no impact on response speed of magnetically controlled reactor.

\section{Conclusions}

Induced voltage at the both ends of exciting winding has larger security threat on exciter circuit or even the magnetically controlled reactor. The main reason of existing induced voltage is caused by bad symmetry of magnetically controlled reactor's manufacturing technique. Improving structure design of magnetically controlled reactor and perfecting symmetry of reactor's 
technological structure are the basic solution to eliminate or reduce exciting winding induced voltage.

Adding offset transformer between the output end of exciter circuit and exciting winding can reduce the amplitude of induced voltage and eliminate the threat of induced voltage. This is a kind of simple and convenient safeguard procedure. 


\section{References}

[1] Zhao Shishuo, Yin Zhongdong, Liu Haipeng. Physical Design and Control Method of Fast Response Magnetically Controlled Reactors[J]. Proceedings of the CSEE, 2013, 33(15): 149155.

[2] Liu Haipeng, Yin Zhongdong, Li Heming, Cao Songwei . Improvement of SMCR response[J]. Electric Power Automation Equipment, 2014, 34(5): 116-120.

[3] Chen Zhenhu, Liang Jiyong,, Huang Xiangwei. Design and application of power system dynamic MCR reactive power compensation device based on[J]. POWER SYSTEM TECHNOLOGY, 2005, 29(7): 82-84.

[4] $\mathrm{Xu} \mathrm{Yi,} \mathrm{Chen} \mathrm{Jianye.} \mathrm{Numerical} \mathrm{and} \mathrm{Experimental} \mathrm{Analysis} \mathrm{of} \mathrm{Magnetically} \mathrm{Controlled}$ Saturated Reactor[J]. CONVERTER TECHNOLOGY \& ELECTRIC TRACTION, 2008, 3: 9-15.

[5] Wang Baoan, Jin Lili, Luo Yaqiao, Xu Bin, Fei Yijun, Yuan Xiaodong. Dynamic reactive power compensation equipment based on magnetically controlled reactor[J]. Electric Power Automation Equipment, 2010, 30(4): 97-100.

[6]Song Jiangbao, Wang Heping, Zhang Zhanyong, Zhao Guosheng . Analytical study of controllable reactor based on three-phase magnetism valve type[J]. POWER SYSTEM PROTECTION AND CONTROL, 2009, 37(23): 20-22, 40.

[7] Chen Xuxuan, Tian Cuihua, Chen Baichao, Liu Yaozhong, Yuan Jia-xin. Mathematical Model for Harmonics Analysis of the Multi-Stage Saturable Magnetic-Valve Controllable Reactor [J]. TRANSACTIONS OF CHINA ELECTROTECHNICAL SOCIETY, 2011, 26(3) : 5764.

[8] Wang Fengxiang, Zhang Tao, Bai Haoran. Multi-phase rectifying system using phase-shifting reactor[J]. JOURNAL OF SHENYANG UNIVERSITY OF TECHNOLOGY, 2008, 30(4): 361-365, 393.

[9] LI Heming, Liu Haipeng, Yin Zhongdong. Design of Control System Based on Magnetically Controlled Reactor[J]. High Voltage Engineering, 2014, 40(1): 275-281.

[10]Yu Mengze, Chen Baichao, Tian Cuihua, Qiu Hao. High Voltage Static Yar Reactive Power Compensator Using Shunt Magnetically Controllable Reactor[J] . HIGH VOLTAGE ENGINEERING, 2009, 35(7): 1770-1775.

[11]Zheng Tao, Zhao Yanjie, Jin Ying, Zhang Zhenhuan, Cui Dawei, Liu Yang. Analysis on and Protective Schemes Against Control Winding Turn-to-turn Fault of Magnetic Controllable Shunt Reactors[J]. Automation of Electric Power Systems, 2014, 38(10): 95-99.

[12]Cai Xuansan, Liu Yuenong. Controllable saturated reactor theory, design and application[ M]. Beijing: China Water Power Press, 2008: 44-52, 104-127.

[13]Chen Baichao. The new Controlled Saturated Reactor Theory and Application[M]. Wuhan: Wuhan university of hydraulic and electric engineering press, 1999: 70-107.

[14]Tian Mingxing, Li Qingfu, Wang Shuhong, The magnetic saturation type controlled reactor is equivalent physical model and mathematical model[J]. Journal of electrotechnics, 2002, 17(4): 18-21.

[15]Wei Yunbing, Li Tao, Zhang Guoliang, Li Ping, Cui Guangzhao. A control method for the magnetic-valve controllable reactor based on instantaneous reactive power theory[J]. Power System Protection and Control, 2011, 39(22): 117-121. 